\title{
Controlled versus free breathing for multiple-breath nitrogen washout in asthma
}
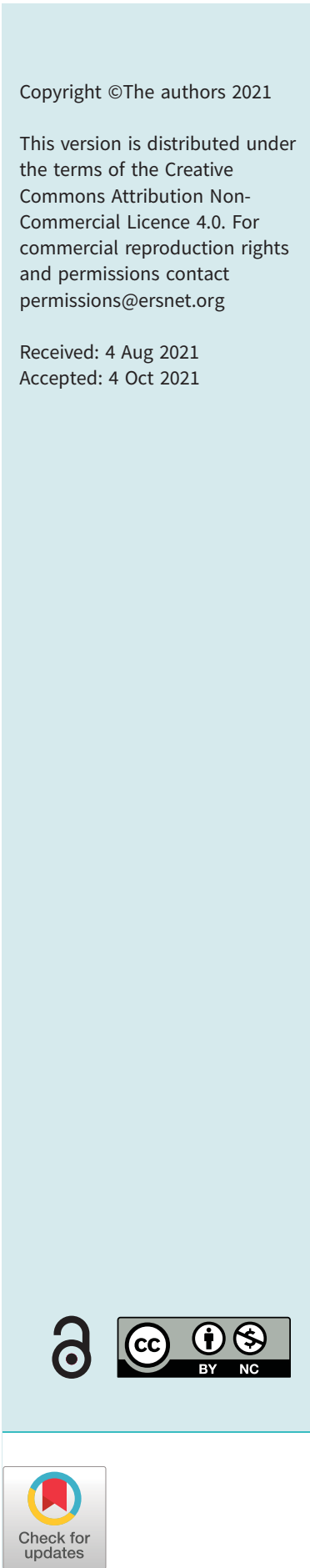

\section{To the Editor:}

Multiple-breath nitrogen washout (MBNW) is an emerging clinical test for assessing ventilation heterogeneity [1], often characteristically increased in asthma. MBNW indices both indicate and predict response to asthma treatment [2-4], and therefore may be an important tool for guiding treatment decisions [2]. Two established breathing protocols are currently in use: 1-L tidal volume $\left(V_{\mathrm{T}}\right)$ controlled breathing (CB) [5, 6] and unrestricted free breathing (FB) [7]. The CB protocol requires targeted $V_{\mathrm{T}}$ and respiratory rate, whereas the FB protocol encourages relaxed tidal breathing, making it more suitable for paediatrics [8]. Two recently published studies in healthy adults showed that indices of conductive and acinar ventilation heterogeneity ( $S_{\text {cond }}$ and $S_{\text {acin }}$, respectively) and, to a lesser extent, lung clearance index (LCI), were not comparable between breathing protocols [9, 10]. Importantly, differences between the protocols were dependent on the magnitude of ventilation heterogeneity. Thus, the assumption is that these effects would be amplified in disease, where ventilation heterogeneity is greater and clinical utility is most relevant. However, this has not been confirmed to date. We hypothesised that people with asthma, where ventilation heterogeneity is greater, would exhibit greater differences between the two protocols than the differences seen in healthy adults.

Therefore, this study aimed to determine in adults with asthma: 1) whether CB and FB MBNW protocols provide comparable functional residual capacity (FRC) and indices of ventilation heterogeneity (LCI, $S_{\text {cond }}$ and $S_{\text {acin }}$ ), and 2) whether patient-related factors (anthropometrics and/or breathing pattern) influence any observable differences.

Written informed consent was obtained from participants with respiratory physician-diagnosed asthma recruited from the Woolcock Institute and Royal North Shore Hospital (ethics approval LNR/16/HAWKE/ 11). The study protocol has been previously published [9]. Briefly, spirometry and plethysmography were obtained according to ATS/ERS standards and current reference values [11, 12]. After a fixed period, participants then performed MBNW according to European Respiratory Society/American Thoracic Society consensus guidelines [8] with either the FB or CB protocol in successive triplicates (Exhalyzer D, collected in Spiroware v3.1.6 and reanalysed in v3.3.1; Eco Medics AG, Duernten, Switzerland), in randomised order. During each trial, once a stable breathing pattern and end-expiratory lung volume (EELV) was established, nitrogen washout during 100\% oxygen inhalation was commenced. The CB protocol required participants to breathe at a respiratory rate between 8 and 12 breaths $\cdot \mathrm{min}^{-1}$, and $V_{\mathrm{T}}$ between 0.95 and $1.3 \mathrm{~L}$ following visual feedback. In the FB protocol, participants were encouraged to adopt relaxed tidal breathing but advised to adjust $V_{\mathrm{T}}$ upwards if insufficient expired nitrogen phase III slope was observed; calculated $S_{\text {cond }}$ and $S_{\text {acin }}$ were adjusted for $V_{\mathrm{T}}$, as per consensus guidelines [8]. At least three technically acceptable trials with FRC values $\pm 10 \%$ of the mean were obtained for each protocol, and quality control and post hoc analysis was performed by a single operator (B.M. Handley). For each MBNW parameter, the mean of three trials was compared between the FB and CB protocols using Pearson's correlation, paired t-tests and Bland-Altman plots. Associations between potential predictors (age, sex, height, body mass index (BMI), respiratory rate and $V_{\mathrm{T}}$ ) and between-protocol differences $(\mathrm{FB}-\mathrm{CB})$ were examined using linear regression.

We studied 20 (16 female and four male) nonsmoking participants with a median (interquartile range) age of 43 (31.5) years and BMI of $25(7.1) \mathrm{kg} \cdot \mathrm{m}^{-2}$. Study participants had mean \pm sD forced expiratory volume

Shareable abstract (@ERSpublications)

The lack of comparability in indices of ventilation heterogeneity between free- and controlledbreathing MBNW protocols is confirmed in asthma https://bit.ly/3lmri4A

Cite this article as: Handley BM, Bozier J, Jeagal E, et al. Controlled versus free breathing for multiplebreath nitrogen washout in asthma. ERJ Open Res 2021; 7: 00487-2021 [DOI: 10.1183/23120541.004872021]. 
in $1 \mathrm{~s}\left(\mathrm{FEV}_{1}\right) 89.2 \pm 19.2 \%$ predicted and $\mathrm{FEV}_{1} /$ forced vital capacity $74.4 \pm 8.35 \%$. Compared to the $\mathrm{CB}$ protocol, the FB protocol had smaller mean $V_{\mathrm{T}}$ (mean \pm SD difference $-0.36 \pm 0.22 \mathrm{~L}, \mathrm{p}<0.0001$ ) and a faster mean respiratory rate (mean \pm SD difference $3.16 \pm 3.33$ breaths $\cdot \mathrm{min}^{-1}, \mathrm{p}=0.029$ ).

There was no significant difference in FRC measured between protocols $\left(\mathrm{FRC}_{\mathrm{CB}} 2.62 \pm 0.72 \mathrm{~L}\right.$ versus $\left.\mathrm{FRC}_{\mathrm{FB}} 2.60 \pm 0.71 \mathrm{~L}, \mathrm{p}=0.64\right)$, with strong correlation between the two $(\mathrm{r}=0.97, \mathrm{p}<0.0001)$ and no evidence of proportional bias in the Bland-Altman plot $(\mathrm{p}=0.81)$ (figure 1a). This is similar to observations in healthy adults [9], and supports the argument that FRC is not altered between MBNW protocols so long as care is taken to ensure stable breathing and EELV before and during washout. Both $\mathrm{FRC}_{\mathrm{CB}}(\mathrm{p}=0.006)$ and $\mathrm{FRC}_{\mathrm{FB}}(\mathrm{p}=0.005)$ were significantly reduced compared to plethysmographic FRC $(2.87 \pm 0.60 \mathrm{~L})$, as may
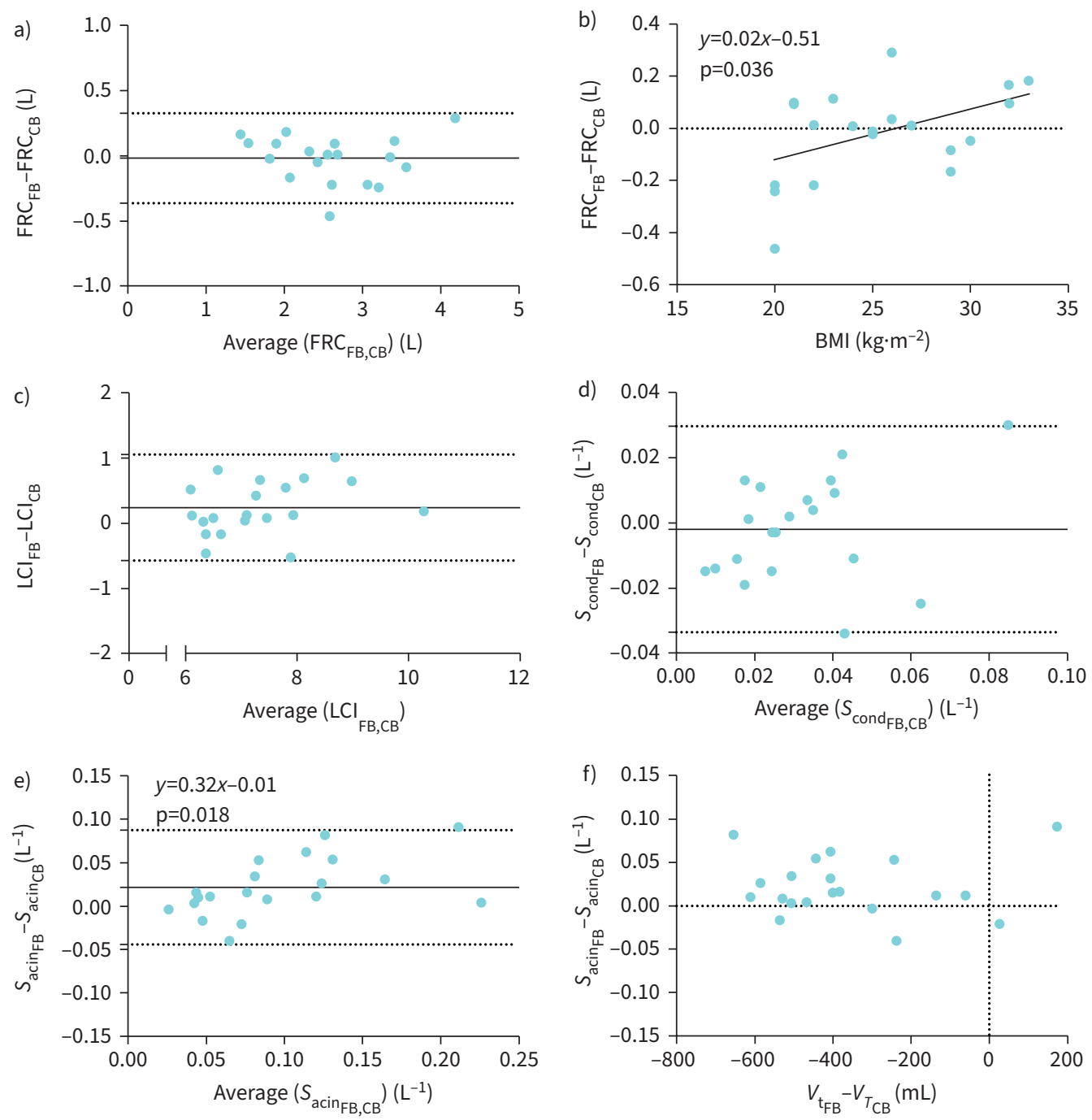

FIGURE 1 Differences between controlled (CB) and free breathing (FB) protocols, and associated factors. a) Functional residual capacity (FRC), showing no significant differences between the two protocols (mean difference (95\% limits of agreement) $-0.019(-0.364-0.327) L, p=0.64)$ and no proportional bias $(p=0.81)$, with b) between-protocol differences in FRC related to body mass index (BMI) $(p=0.036)$. c) Lung clearance index $(\mathrm{LCl})$, showing significant differences $(0.235(-0.578-1.048), \mathrm{p}=0.020)$ but no proportional bias $(\mathrm{p}=0.179)$ between protocols. d) Conductive ventilation heterogeneity $\left(S_{\text {cond }}\right)$, showing no significant differences between protocols $\left(-0.0020(-0.034-0.030) L^{-1}, p=0.59\right)$ and no proportional bias $(p=0.203)$. e) Acinar ventilation heterogeneity $\left(S_{\text {acin }}\right)$ was significantly different between protocols $\left(0.0215(-0.044-0.087) L^{-1}, p=0.01\right)$ with a significant proportional bias $(p=0.018)$, and $f$ ) between-protocol differences in $S_{\text {acin }}$ were not predicted by between-protocol differences in tidal volume $\left(V_{T_{F B}}-V_{T_{C B}}\right)(p=0.98)$ or respiratory rate ( $p=0.38$, data not shown). 
be expected in disease from a gas dilution method reliant on communicating lung volume. Interestingly, within-subject differences in FRC between protocols were associated with BMI $(y=0.02 x-0.51, \mathrm{p}=0.036)$ (figure $1 \mathrm{~b}$ ) but not with age, sex, height, mean $V_{\mathrm{T}}$ or mean respiratory rate. We had previously found a trend towards a significance relationship between BMI and between-protocol differences in FRC [9]. The association we observed in this study could be attributed to a wider range for BMI, with more obese participants exhibiting higher $\mathrm{FRC}_{\mathrm{FB}}$ values. The mechanisms for this are unknown but may have implications for testing in a clinical population.

Significant differences were seen in LCI between protocols, with higher values obtained using $\mathrm{FB}$ ( $\mathrm{LCI}_{\mathrm{CB}}$ $7.23 \pm 1.04$ versus $\mathrm{LCI}_{\mathrm{FB}} 7.46 \pm 1.17, \mathrm{p}=0.020$ ), but the two protocols were strongly correlated $(\mathrm{r}=0.94$, $\mathrm{p}<0.0001$ ). This finding was consistent with our previous findings in health [9] except that now there was no proportional bias between protocols in asthma evident $(\mathrm{p}=0.179)$ (figure 1c). Previous studies suggested an effect of changing $V_{\mathrm{T}}$ on LCI [13], where shallow breathing may contribute to a higher LCI through an increased dead space to $V_{\mathrm{T}}$ ratio, and its effects on FRC and cumulative expired volume; though this effect was not statistically significant in our data. However, as we also previously demonstrated in health [9] and the lack of differences observed in other studies [14], the mean difference of $0.23 \pm 0.41$ seen here was relatively small and unlikely to be clinically significant. For comparison, the minimal clinically important difference for MBNW is yet to be established, however, a change of 1 unit is often used for LCI in interventional studies [15].

Results for $S_{\text {cond }}$ and $S_{\text {acin }}$ were also similar to those observed in health. $S_{\text {cond }}$ was not significantly different between the $\mathrm{CB}$ and FB protocols $\left(S_{\text {cond }_{\mathrm{CB}}} 0.033 \pm 0.018 \mathrm{~L}^{-1}\right.$ versus $S_{\text {cond }_{\mathrm{FB}}} 0.031 \pm 0.022 \mathrm{~L}^{-1}$, $\mathrm{p}=0.59)$, with significant correlation between the two $(\mathrm{r}=0.70, \mathrm{p}=0.0006)$ and no evidence of proportional bias $(\mathrm{p}=0.20)$ (figure $1 \mathrm{~d})$. In contrast, $S_{\text {acin }}$ was significantly different between the protocols $\left(S_{\text {acin }}\right.$ $0.086 \pm 0.05$ versus $S_{\mathrm{acin}_{\mathrm{FB}}} 0.108 \pm 0.07, \mathrm{p}=0.01$ ), with significant correlation between the two ( $\mathrm{r}=0.87$, $\mathrm{p}<0.0001)$, but evidence of proportional bias $(y=0.32 x-0.01, \mathrm{p}=0.018)$ (figure 1e). These findings are consistent with the larger differences expected from the proportional bias observed in health [9, 10], particularly for $S_{\text {acin }}$. Neither between-protocol differences in $S_{\text {cond }}$ nor in $S_{\text {acin }}$ had any associations with age, sex, height, BMI, mean $V_{\mathrm{T}}$ or mean respiratory rate. The lack of dependence on breathing pattern in asthma is contrary to what we observed in health for $S_{\text {acin }}$ and may suggest that the contribution of disease to between-protocol differences is larger than that of the breathing pattern. Alternatively, this could have been skewed by one individual whose $V_{\mathrm{T}}$ was greater during $\mathrm{FB}$ than $\mathrm{CB}$ (figure 1f).

It is interesting to note that the magnitudes of the between-protocol differences and limits of agreement seen in this study in asthma $\left(-0.0020(-0.034-0.030) \mathrm{L}^{-1}\right.$ for $S_{\text {cond }}$ and $0.0215(-0.044-0.087) \mathrm{L}^{-1}$ for $\left.S_{\text {acin }}\right)$ were similar in range to those published in health $\left(0.0002(-0.030-0.030) \mathrm{L}^{-1}\right.$ for $S_{\text {cond }}$ and 0.029 $(-0.045-0.103) \mathrm{L}^{-1}$ in $\left.S_{\text {acin }}\right)$ [9], despite the larger $S_{\text {cond }}$ and $S_{\text {acin }}$ values. A possible explanation may again be that the degree of abnormal ventilation distribution due to asthma is a stronger contributor to the measured $S_{\text {cond }}$ and $S_{\text {acin }}$ than variations in the breathing pattern. It is also possible that relative variability is lower in disease, unlike in health, where the small values of $S_{\text {cond }}$ and $S_{\text {acin }}$ close to zero render any variations proportionately larger.

We do not have data on between-session repeatability in these patients, although published studies exist for comparison [9, 16]. The between-protocol differences and limits of agreement seen here were similar or larger than previously reported between-session repeatability for the MBNW test in health $(-0.003$ $(-0.021-0.015) \mathrm{L}^{-1}$ for $S_{\text {cond }}$ and $-0.002(-0.039-0.034) \mathrm{L}^{-1}$ for $S_{\text {acin }}$ over 2-10 weeks) [9] but less than the between-session repeatability in asthma $\left(0.004(-0.072-0.079) \mathrm{L}^{-1}\right.$ for $S_{\text {cond }}$ and $-0.024(-0.156-$ $0.108) \mathrm{L}^{-1}$ for $S_{\text {acin }}$ over 2 weeks) [16], reflecting contributions from protocol differences, test variability and disease.

The limitations of this study include the small sample size and the high proportion of participants who had undergone lung function testing before, although 15 out of 20 were naïve to MBNW. Nevertheless, these data confirm in disease that the two protocols should not be simply treated interchangeably in prospective studies, with implications for the interpretation of previously published data. It should also be noted that the data presented in this study were analysed using the updated software version for the Exhalyser D device, which takes into account a recently documented sensor error [17, 18]; comparisons with health are also based on updated results, for which a correction has been issued. Further work is warranted to better understand the applicability of the $V_{\mathrm{T}}$ correction [10], dependence on phase III slope estimation [19] and other possible sources contributing to differences between these two established MBNW protocols. 
Blake M. Handley ${ }^{1,2,6}$, Jack Bozier ${ }^{1,2,6}$, Edward Jeagal ${ }^{1,3}$, Sandra Rutting $\oplus^{1,2}$, Robin E. Schoeffel ${ }^{2}$, Paul D. Robinson ${ }^{1,4}$, Gregory G. King ${ }^{1,2}$, Stephen Milne ${ }^{1,5,7}$ and Cindy Thamrin $\mathbb{1}^{1,7}$

${ }^{1}$ Woolcock Institute of Medical Research, University of Sydney, Glebe, NSW, Australia. ${ }^{2}$ Dept of Respiratory Medicine, Royal North Shore Hospital, St Leonards, NSW, Australia. ${ }^{3}$ University of Technology Sydney, School of Life Sciences, Sydney, NSW, Australia. ${ }^{4}$ Dept of Respiratory Medicine, The Children's Hospital at Westmead, Westmead, NSW, Australia. ${ }^{5}$ Centre for Heart Lung Innovation, St Paul's Hospital and Division of Respiratory Medicine, University of British Columbia, Vancouver, BC, Canada. ${ }^{6}$ These first authors contributed equally. ${ }^{7}$ These senior authors contributed equally.

Corresponding author: Cindy Thamrin (cindy.thamrin@woolcock.org.au)

Provenance: Submitted article, peer reviewed.

Conflicts of interest: B.M. Handley has nothing to disclose. J. Bozier has nothing to disclose. E. Jeagal has nothing to disclose. S. Rutting has nothing to disclose. R.E. Schoeffel has nothing to disclose. P.D. Robinson has nothing to disclose. G.G. King reports fees for consultancy services, conference attendance support and unrestricted research grants from AstraZeneca, Boehringer Ingelheim, CycloPharm, GlaxoSmithKline, Novartis, Menarini, MundiPharma. G.G. King also reports NHMRC research grants and fellowships. S. Milne has nothing to disclose. C. Thamrin reports supply of equipment for an unrelated study from Restech SRL. C. Thamrin also reports funded research collaboration for an unrelated project.

\section{References}

1 King GG. Cutting edge technologies in respiratory research: lung function testing. Respirology 2011; 16: 883-890.

2 Farah CS, King GG, Brown NJ, et al. Ventilation heterogeneity predicts asthma control in adults following inhaled corticosteroid dose titration. J Allergy Clin Immunol 2012; 130: 61-68.

3 Tang FSM, Rutting S, Farrow CE, et al. Ventilation heterogeneity and oscillometry predict asthma control improvement following step-up inhaled therapy in uncontrolled asthma. Respirology 2020; 25: 827-835.

4 Farah CS, Badal T, Reed N, et al. Mepolizumab improves small airway function in severe eosinophilic asthma. Respir Med 2019; 148: 49-53.

5 Verbanck S, Thompson BR, Schuermans D, et al. Ventilation heterogeneity in the acinar and conductive zones of the normal ageing lung. Thorax 2012; 67: 789-795.

6 Verbanck S, Van Muylem A, Schuermans D, et al. Transfer factor, lung volumes, resistance and ventilation distribution in healthy adults. Eur Respir J 2016; 47: 166-176.

7 Kjellberg S, Houltz BK, Zetterström 0 , et al. Clinical characteristics of adult asthma associated with small airway dysfunction. Respir Med 2016; 117: 92-102.

8 Robinson PD, Latzin P, Verbanck S, et al. Consensus statement for inert gas washout measurement using multiple- and single- breath tests. Eur Respir J 2013; 41: 507-522.

9 Handley BM, Jeagal E, Schoeffel RE, et al. Controlled versus free breathing for multiple breath nitrogen washout in healthy adults. ERJ Open Res 2020; 7: 00435-2020.

10 Verbanck S, Schuermans D, Paiva M, et al. Mitigating increased variability of multiple breath washout indices due to tidal breathing. Eur Respir J 2021; 57: 2002765.

11 Quanjer PH, Stanojevic S, Cole TJ, et al. Multi-ethnic reference values for spirometry for the 3-95-yr age range: the global lung function 2012 equations. Eur Respir J 2012; 40: 1324-1343.

12 Quanjer PH, Tammeling GJ, Cotes JE, et al. Lung volumes and forced ventilatory flows. Eur Respir J 1993; 6: Suppl. 16, 5-40.

13 Ratjen F, Jensen R, Klingel M, et al. Effect of changes in tidal volume on multiple breath washout outcomes. PLOS ONE 2019; 14: e0219309.

14 Prisk GK, Petersen GM, Geier ET, et al. Ventilatory heterogeneity in the normal human lung is unchanged by controlled breathing. J Appl Physiol. 2020; 129: 1152-1160.

15 Short C, Saunders C, Davies JC. Utility of lung clearance index in CF: What we know, what we don't know and musings on how to bridge the gap. J Cyst Fibros 2020; 19: 852-855.

16 Gonem S, Corkill S, Singapuri A, et al. Between-visit variability of small airway obstruction markers in patients with asthma. Eur Respir J 2014; 44: 242-244.

17 Sandvik RM, Gustafsson PM, Lindblad A, et al. Improved agreement between $\mathrm{N}_{2}$ and $\mathrm{SF}_{6}$ multiple-breath washout in healthy infants and toddlers with improved EXHALYZER D sensor performance. J Appl Physiol (1985) 2021; 131: 107-118. 
18 Wyler F, Oestreich M-AH, Frauchiger BS, et al. Correction of sensor crosstalk error in Exhalyzer D multiple-breath washout device significantly impacts outcomes in children with cystic fibrosis. J Appl Physiol (1985) 2021; 131: 1148-1156.

19 Bates JHT, Peters U. A model-based approach to interpreting multibreath nitrogen washout data. J Appl Physiol 2018; 124: 1155-1163. 